\title{
Computational study of the effect of trees on wind flow over a building
}

\author{
Mohamed Arif Mohamed and David H Wood*
}

\begin{abstract}
A computational study was performed to investigate the effect of varying upwind tree heights on the wind flow over a 15-m high, flat-roof building. It is shown that trees can have a significant effect on the mean wind speed and turbulence over the roof and should be included when performing a computational fluid dynamics simulation. The calculations also provide guidance for undertaking wind tunnel experiments on simulated trees and buildings to investigate their interaction. The effect of the trees on the mean wind speed above the roof was not a monotonic function of ratio of tree-to-building height. Further, the trees reduced the level of turbulence over the roof. The study also confirmed that the production of turbulent kinetic energy by the trees and its subsequent advection over the building are the main causes of the modified flow.
\end{abstract}

Keywords: Trees; CFD; Buildings; Log law; Wind resource assessment; Building-mounted wind turbines; Photovoltaic arrays

\section{Background}

The roofs of buildings provide many opportunities for renewable energy generation, all of which require knowledge of the wind flow and turbulence. This is obvious for building-mounted wind turbines, but photovoltaic and solar thermal installations can often experience high wind loads and may incur significant structural costs to withstand them. In many cases, buildings are close to trees which, if upwind of the building, can significantly alter the wind flow.

Wind flows around trees are characterized by vortex shedding, high drag, and complex wake turbulence. Surprisingly, many computational fluid dynamics (CFD) simulations involving the urban landscape do not model trees viz Blocken et al. (2012) and Tabrizi et al. (2014). In some cases, it is possible to treat trees as a porous surface (Hakimi and Lubitz 2014). Excluding trees will lead to errors because their wakes persist a long downstream distance in terms of velocity deficit and increased turbulence, (Ishikawa et al. 2006). Knowledge of the wake is likely to be important in deciding where to erect a small wind turbine whose hub height is comparable to that of surrounding trees. Kalmikov et al. (2010) modeled trees in a simulation

\footnotetext{
*Correspondence: dhwood@ucalgary.ca

Dept. of Mechanical and Manufacturing Engineering, University of Calgary,

2500 University Dr, NW, Calgary T2N 1N4, Alberta, Canada
}

over the Massachusetts Institute of Technology campus by introducing a sink term in the momentum equation but did not account for the effect on the turbulent kinetic energy, $k$.

Much work has been done on the effects of vegetative canopies on the atmospheric boundary layer, e.g., Raupach and Shaw (1982), Finnigan and Shaw (2008), etc. The introduction of form drag within a canopy is purported to convert the mean kinetic energy and large scale $k$ to its form at smaller scales (Wilson and Shaw 1977). However, this paper will consider only individual trees and their effects on the wind flow over a single generic building. The study is entirely computational, using the well-known $k-\epsilon$ turbulence model, where $\epsilon$ is the dissipation. It has two major aims, first to demonstrate the importance of trees for the roof flow, and, second, to give guidance for further investigation by wind tunnel experiments.

The computational modeling of trees is described in the next section. 'The modeled building and computational domain' subsection outlines the generic building and the upwind trees of varying height. The results and discussion are contained in the 'Results and discussion' section which is followed by the conclusions.

\section{量 Springer}

(c) 2015 Mohamed and Wood; licensee Springer. This is an Open Access article distributed under the terms of the Creative Commons Attribution License (http://creativecommons.org/licenses/by/4.0), which permits unrestricted use, distribution, and reproduction in any medium, provided the original work is properly credited. 


\section{Methods}

\section{Modeling of trees}

Amorim et al. (2013) accounted for the loss of momentum by introducing a sink term in the momentum equations. As mentioned earlier, by doing this, $k$ is suppressed. To counteract this, a source term was added to the $k$ budget. They introduced a parameter, $\beta_{p}$, which represents the fraction of the mean flow kinetic energy that is converted to the wake $k$. They also included a parameter, $\beta_{d}$, which accounts for the $k$ dissipated through the 'shortcircuiting' of the energy cascade from the large to small eddies. Amorim et al. (2013) modeled the sink term for the momentum equations as

$$
S_{d}=C_{d} \mathrm{LAD}|U| u_{i},
$$

where LAD is the leaf area density, $|U|$ is the wind speed, $C_{d}$ is the drag coefficient, and $u_{i}$ represents the velocity components. The source terms to be added to the transport equations for turbulent kinetic energy and dissipation rate in the $k-\epsilon$ model are

$$
S_{k}=C_{d} \operatorname{LAD}\left(\beta_{p}|U|^{3}-\beta_{d}|U| k\right),
$$

and

$$
S_{\epsilon}=C_{d} \operatorname{LAD}\left(E_{1} \beta_{p}|U|^{3} \frac{\epsilon}{k}-E_{1} \beta_{d}|U| \epsilon\right) .
$$

Amorim et al. (2013) gave $\beta_{p}, \beta_{d}$, and the constant $E_{1}$ in Equation (3) as 1, 4, and 1.5 respectively. These values were used in the present calculations.

\section{Leaf area density}

The LAD is a ratio of the leaf covered area per unit volume of one side of the foliage. It is used in transpiration and photosynthesis models by tree scientists, and it determines the porosity of the tree viewed from the angle corresponding to the side. It is not to be confused with the leaf area index (LAI) which is defined as 'the leaf area per unit of ground area covered by the projected area of the crown', (Hosoi and Omasa 2009). Lalic and Mihailovic (2004) proposed an empirical equation for LAD

$$
\begin{aligned}
& \mathrm{LAD}=\operatorname{LAI}\left(\frac{h_{t}-z_{m}}{h_{t}-z}\right)^{n} \exp \left[n\left(1-\frac{h_{t}-z_{m}}{h_{t}-z}\right)\right], \\
& n= \begin{cases}6 & 0 \leq z<z_{m} \\
0.5 & m \leq z<h_{t},\end{cases}
\end{aligned}
$$

where $h_{t}$ is the tree height and $z_{m}$ is the height at which LAD is maximum. Kolic (1978) provided a classification for $z_{m}$ for a number of trees. This is shown in the Table 1.

The trees were modeled by Equations (1) to (3). As mentioned earlier, one of the components in the momentum sink term in Equation (1) includes the coefficient of drag. This value was obtained from the experiments of Ishikawa et al. (2006) for a conifer and shown in Figure 1. The value
Table 1 Characterization of $z_{m}$ for different trees

\begin{tabular}{lc}
\hline Type of trees & $\boldsymbol{z}_{\boldsymbol{m}}$ \\
\hline Oak and silver birch & $0.2 \mathrm{~h}$ \\
Common maple & $0.2 \mathrm{~h}<z_{m}<0.4 h_{t}$ \\
Pine & $0.4 h_{t}$ \\
\hline
\end{tabular}

chosen here was 1.28. This was based on a freestream velocity of $5 \mathrm{~m} / \mathrm{s}$ at the crown of the tree.

The leaf area index, which is an input to calculate the leave area density in Equation (4), was taken from the website (http:na.fs.fed.us/fhp/eab/pubs/chicago_ash/ chic_ash.shtm).

\section{The flow downstream of a single tree}

Initial calculations were performed of the wake of a single conifer modeled as a rectangular block. It was set as a fluid region with added sink and source terms to the momentum, $k$ and $\epsilon$ equations. These calculations, as all calculations presented in this paper, used the standard $k$ and $\epsilon$ model constants, as given, for example by Launder (1972). The computational domain is shown in Figure 2.

The inlet boundary conditions followed the log-law for the velocity, $U$, and assumed the usual balance between production and dissipation of $k$ to determine their profiles

$$
\begin{aligned}
& U=\frac{u_{\tau}}{\kappa} \ln \left(\frac{z}{z_{0}}\right), \\
& k=\frac{u_{\tau}^{2}}{\sqrt{C_{\mu}}}, \\
& \epsilon=\frac{u_{\tau}^{3}}{\kappa z},
\end{aligned}
$$

where $u_{\tau}, z_{0}, \kappa$, and $C_{\mu}$ are the friction velocity, roughness length, the von Kármán, and model constant, respectively.

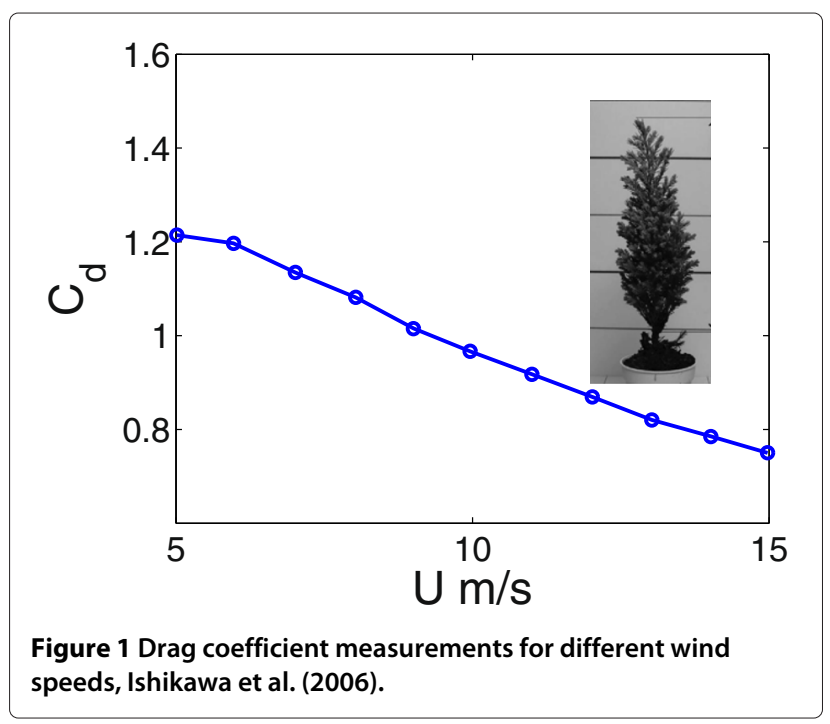




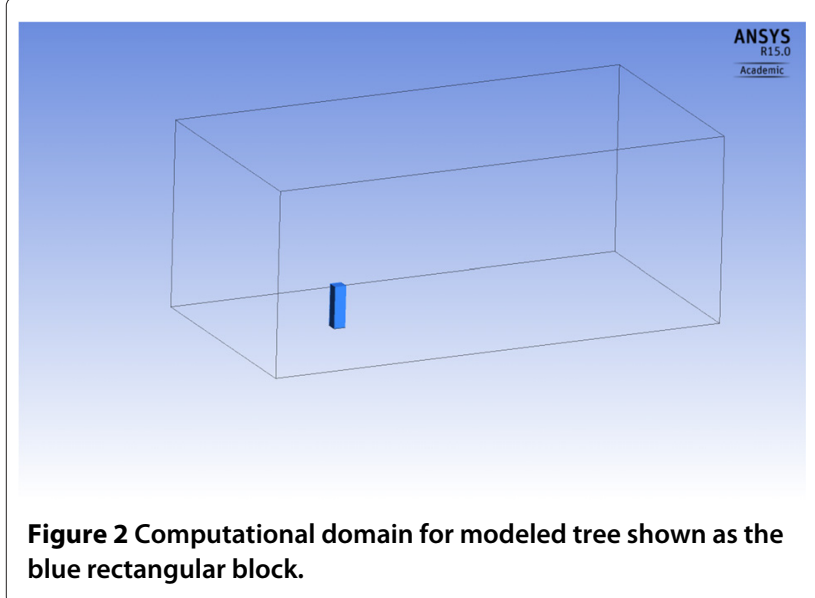

The values for $u_{\tau}$ and $z_{0}$ were set to $0.3 \mathrm{~m} / \mathrm{s}$ and $0.04 \mathrm{~m}$, respectively, which are typical values obtained from wind mast measurements at Spyhill in North Calgary. Velocity profiles were extracted in the wake of the tree and are shown in Figure 3. The reference wind speed $U_{e}$ was $m, x$, and $y$ are the streamwise and spanwise directions, respectively, and $d$ is the diameter of the tree which was set to 5 $\mathrm{m}$. The origin for the co-ordinates is the center of the tree in the horizontal plane. The wind speed in the absence of the tree was $U / U_{e}=* *$.

The velocity profiles along the wake at the midheight of the 18-m high tree are similar to the wind tunnel measurements of Ishikawa et al. (2006) . The flow relaxes by $x / d=10$. That is to say it shows almost a flat profile signifying the recovery of the velocity deficit. The $k$ profiles were also shown in Figure 4. The maximum occurred at the nearest downwind distance of the tree.

Figure 5 shows the vertical distribution of the wake velocity at $z=0$ width $x / d=-4$ giving the upwind

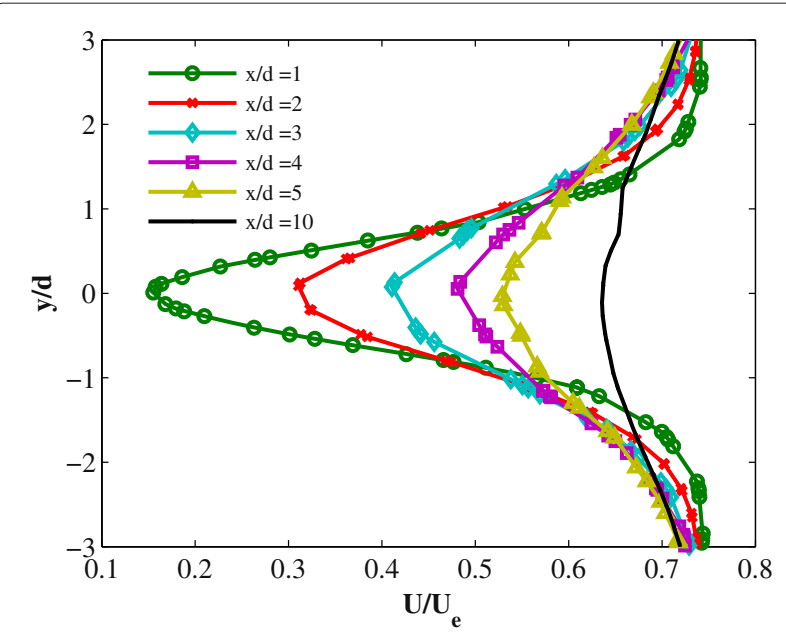

Figure 3 Velocity profiles along the wake of an 18-m single tree at midheight.

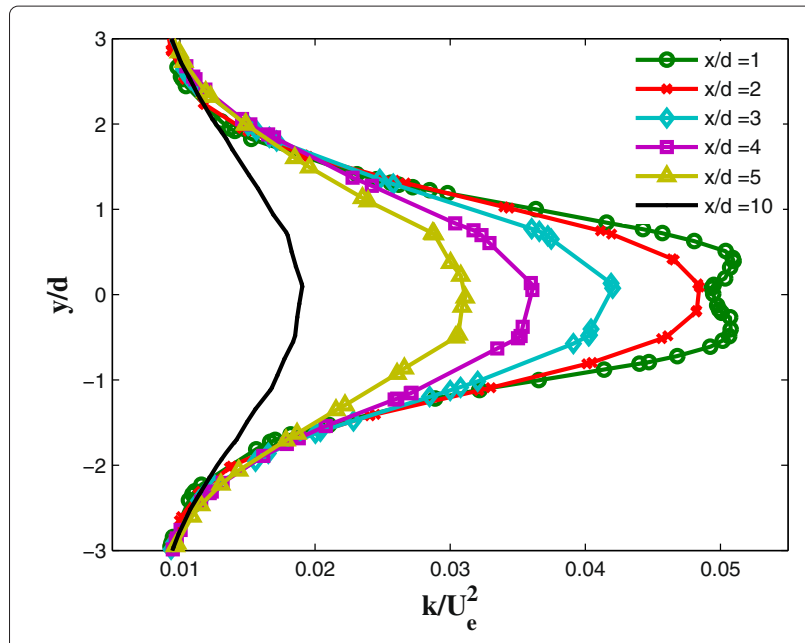

Figure 4 TKE profiles along the wake of a single tree.

profile. As shown, the velocity deficit is still not recovered even at $x / d=10$ at tree height. Interestingly enough, above $z / h=1$, the wind speed first increases and then decreases relative to the undisturbed flow.

\section{The modeled building and computational domain}

The building was 40-m wide by 50-m in streamwise length and $15-\mathrm{m}$ high, $h_{b}$. Three trees, spaced $12.5 \mathrm{~m}$ apart placed $40 \mathrm{~m}$ upwind of the start of the building. The computational model is shown in Figure 6. Flow in the direction of the positive $x$-axis was the only one case considered.

To prevent an over-prediction of fluid acceleration, the top of the computational domain was placed $5 h_{b}$ away from the roof of the building, where $h_{b}$ is the building height. The blockage ratio of the computational domain

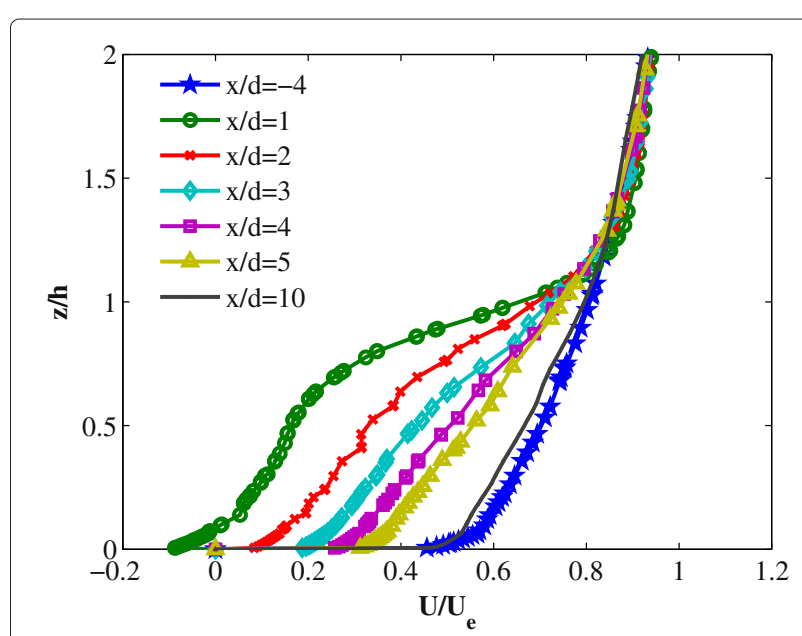

Figure 5 Vertical distribution of streamwise velocity along the centerline of the wake of a single tree. 


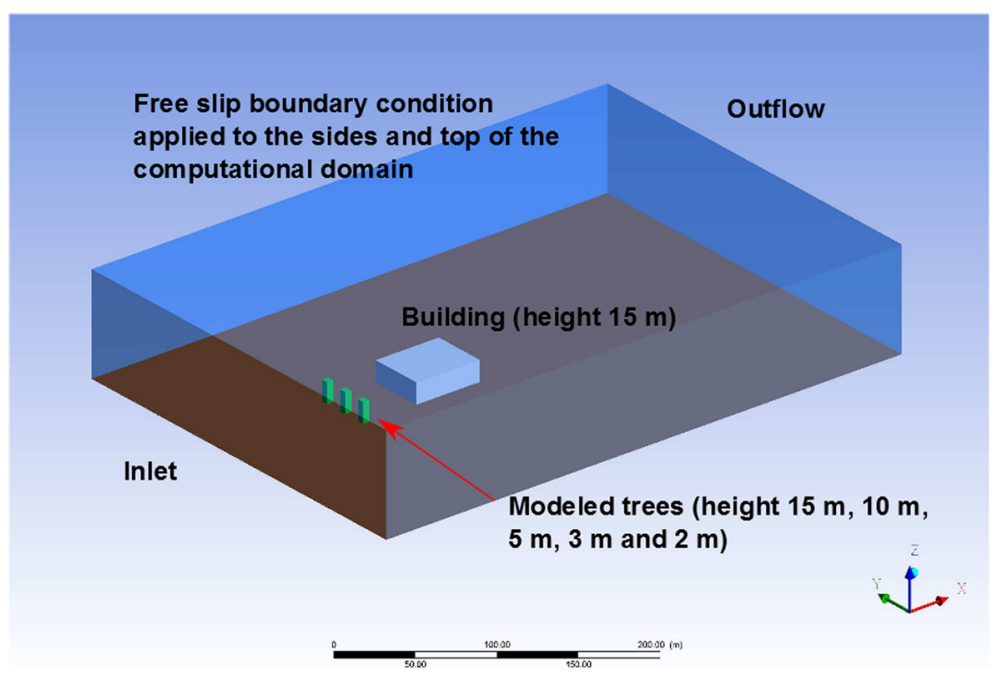

Figure 6 Computational domain used for the study of the effects of trees on a single building.

was 3\%, as recommended by Franke et al. (2004) for building flow simulations. The description of the computational domain is summarized in Table 2. The conditions at each boundary were based on the recommendations of Franke et al. (2004).

Prior to simulating the effect of trees, a grid dependence test was performed. Three grid sizes were analyzed and the results are shown in Figure 7 . The velocity profile was taken at the midpoint of the roof, defined as $x / d=0.5$ where $d=50 \mathrm{~m}$ is the streamwise distance of the building. $z=0$ at the roof surface. The hexahedral grid chosen for the study consisted of $2,278,780$ nodes.

The maximum $y^{+}$on the roof of the building was 11.067 based on the $k-\epsilon$ turbulence model. The advection scheme and turbulence numerics were based on the high resolution scheme in ANSYS CFX 15. The convergence criterion was set to $1 e-6$.

The simulations with varying $h_{t} / h_{b}$ ratio used the same mesh. The height of the tree, $h_{t}$, was varied based on the formulation of Equation (4).

\section{Results and discussion}

Figures 8, 9, 10, and 11 display wind speed and $k$ for $y=0$ with and without the $15-\mathrm{m}$ trees which are

Table 2 Description of computational domain

\begin{tabular}{lll}
\hline Boundary & Boundary Condition & Location \\
\hline Inlet & Equations (6) to (8) & $5 h_{b}$ away from building \\
Top & Free slip & $5 h_{b}$ away from building \\
Sides & Free slip & \\
Floor & No slip & - \\
& Scalable wall function & \\
\hline
\end{tabular}

delineated by the black rectangular block. It is apparent that the convection of the wake of the trees downstream has disrupted the flow considerably compared to the case without trees. In the stagnation region at the start of the building, there is a significant reduction of $k$ due to the trees.

$U$ and $k$ for all tree heights considered, including no trees, are plotted in Figures 12, 13, 14, 15, 16, and 17 at three different locations along the roof: near the front at $x / d=0.04$; the midpoint, $x / d=0.5$; and towards the rear at and $x / d=0.75$. The origin for $x$ is the front of the building.

Figure 12 shows that below $z / h_{b} \sim 1.5$ the largest velocity reduction occurs for $h_{t} / h_{b}=1$ when compared to flow

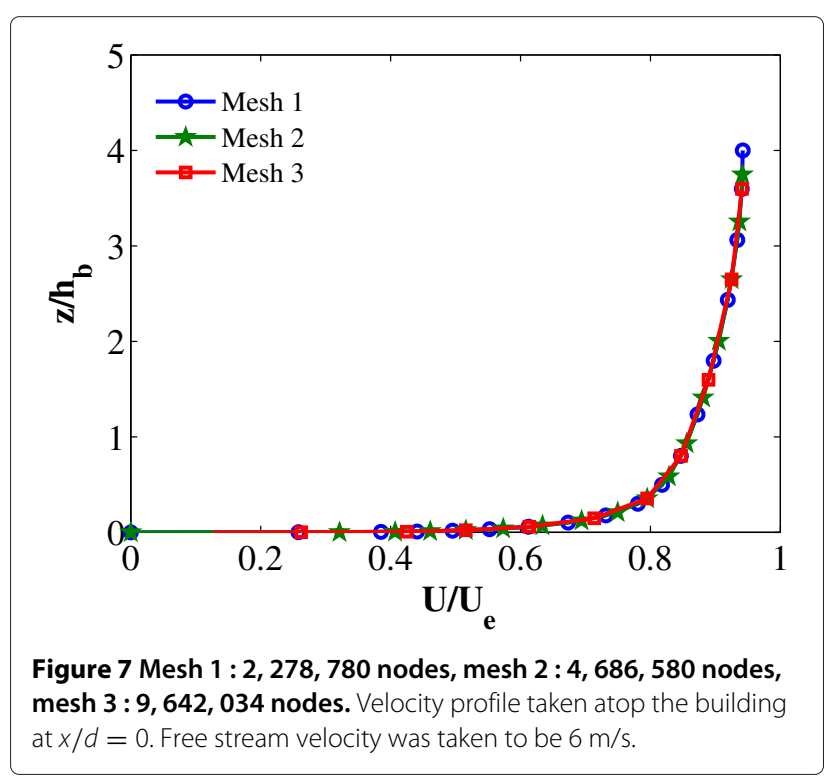




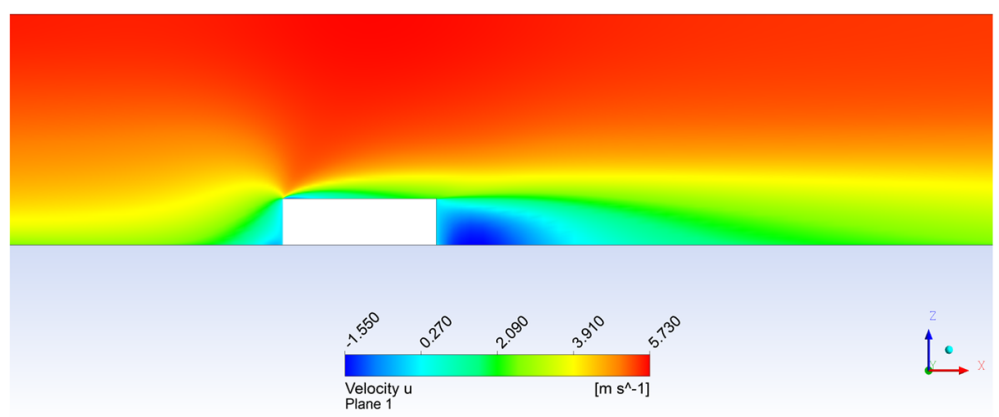

Figure 8 Contours of wind speed with no trees.

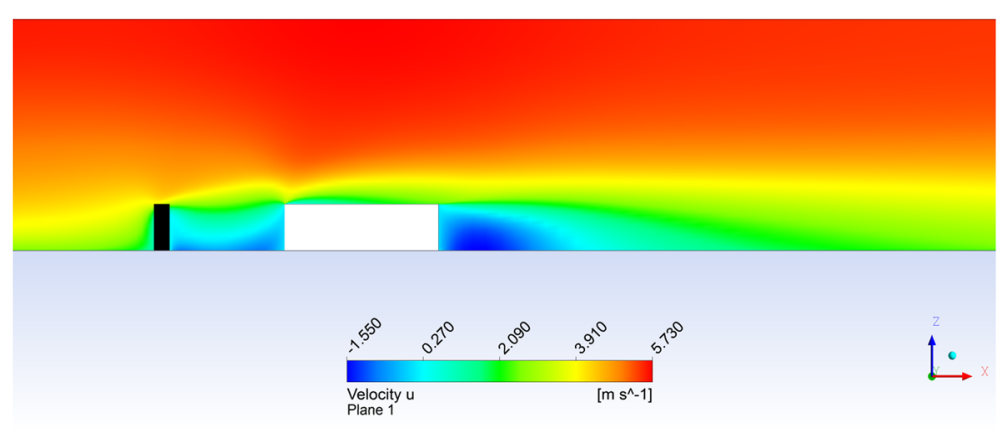

Figure 9 Contours of wind speed with 15-m height trees.

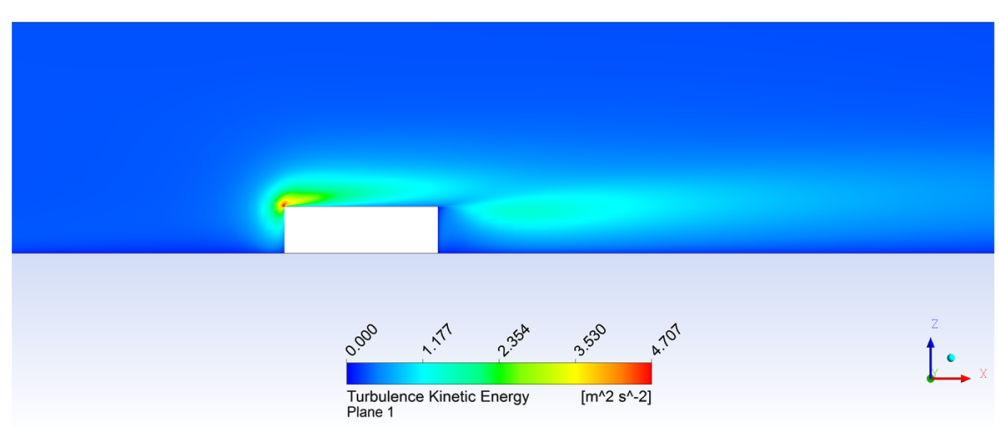

Figure 10 Contours of $k$ with no trees.

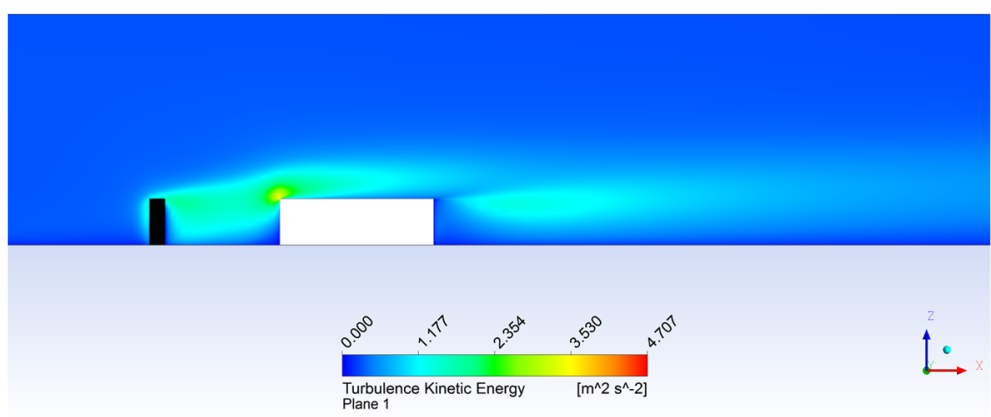

Figure 11 Contours of $k$ with $15-m$ trees. 


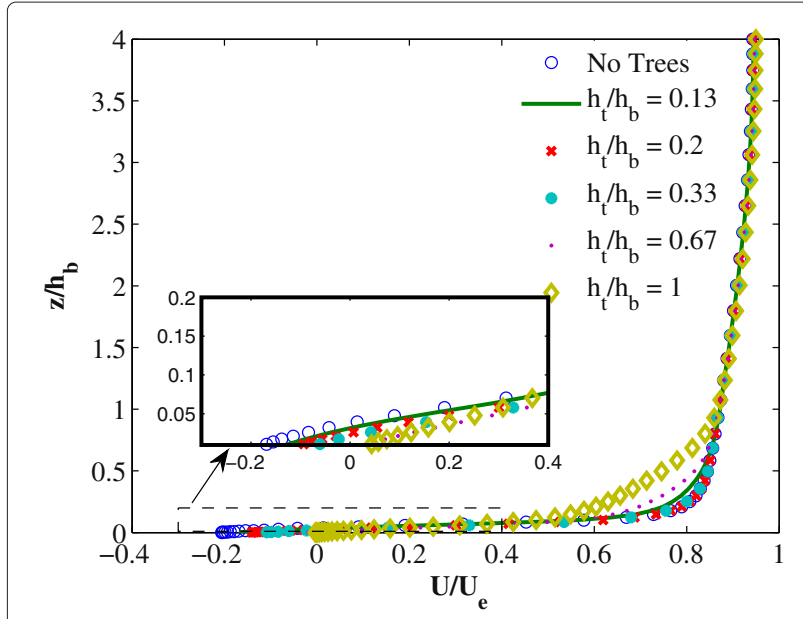

Figure 12 Vertical distribution of wind speed along $x / d=0.04$

without trees. This was expected as was the largely monotonic increase in $U$ as $h_{t}$ decreased. Although the profiles do not exhibit a negative $\partial U / \partial z$, which is typical of mean flow over hills and buildings, e.g., Mohamed and Wood (2013), they do show that trees placed $40 \mathrm{~m}$ away from a $15-\mathrm{m}$ building play an important part in determining the flow field over the front of the roof. The inset to Figure 12 shows that for $z / h_{b}<0.67$, there is a small recirculation region immediately above the roof.

The vertical distribution of $k$ in Figure 13 follows the reverse trend as in $k$ reduces with increasing $h_{t} / h_{b}$. The mechanism for this loss of $k$ when the trees increase the turbulence will be discussed below.

Figures 14 and 15 show the wind speed and turbulence at the midpoint of the roof. The interesting result here is that the velocity profile appears to be same for $h_{t} / h_{b}$ less than 0.67 and then similar for $h_{t} / h_{b}=1.0$ with a significant increase for $h_{t} / h_{b}=0.67$.

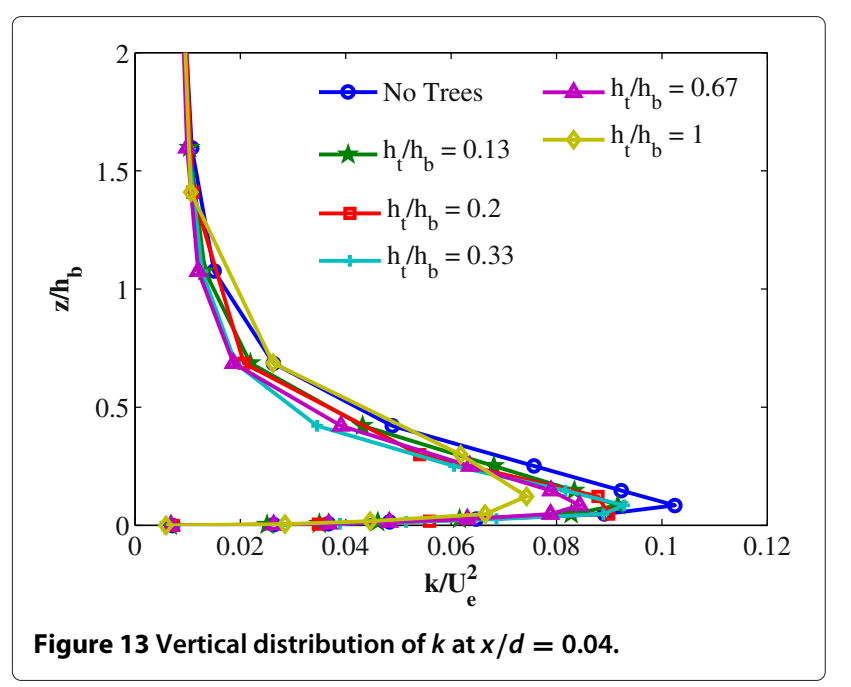

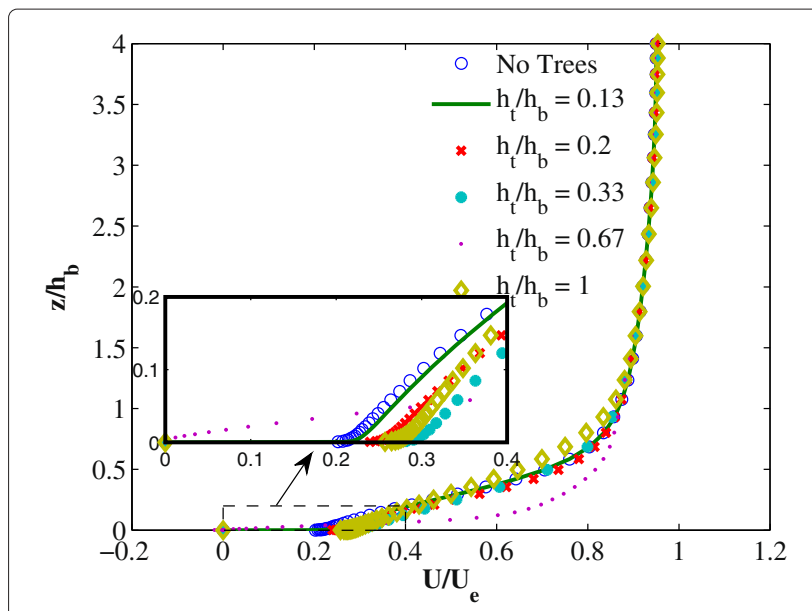

Figure 14 Vertical distribution of wind speed at $x / d=0.5$

The $k$ profiles at $x / d=0.5$ show that $h_{t} / h_{b}=0.67$ has smaller turbulence near the roof compared to all other $h_{t} / h_{b}$. Despite the treeless flow again having the maximum $k$, the trend in $k$ vs $h_{t} / h_{b}$ is not monotonic as it was near the front of the building. The plots for $x / d=0.75$ are shown in Figures 16 and 17. Barring a slight discrepancy for $h_{t} / h_{b}=1$, all the wind speed profiles appear to collapse. The $k$ profiles show the same trend as Figure 15 albeit with a positive sharp gradient in the region $0.4 \leq$ $z / h_{b} \geq 0.6$.

The general, and somewhat surprising, result that trees reduce $k$ can be analyzed further through the energy budget which we now compare for the treeless flow and $h_{t} / h_{b}=1$.

Because the flow is three-dimensional, the advection of $k$ is

$$
U \frac{\partial k}{\partial x}+V \frac{\partial k}{\partial y}+W \frac{\partial k}{\partial z}
$$

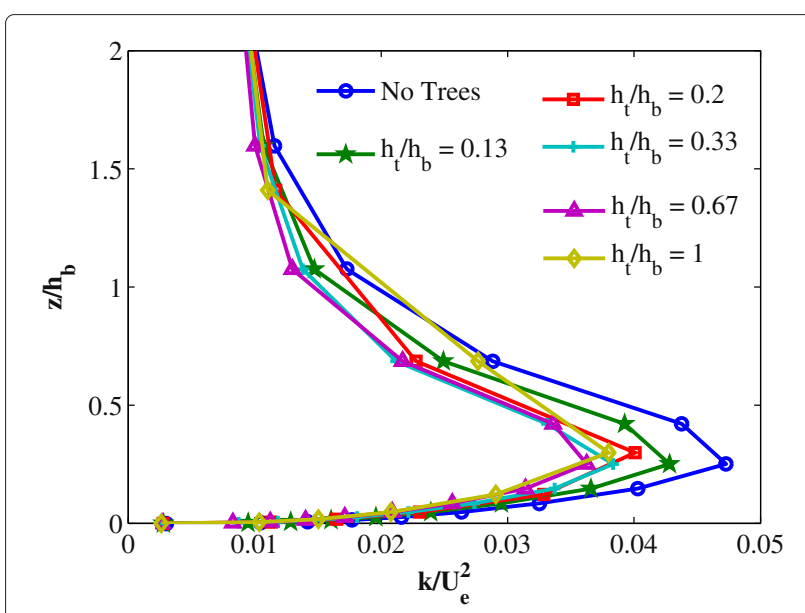

Figure 15 Vertical distribution of $k$ at $x / d=0.5$. 

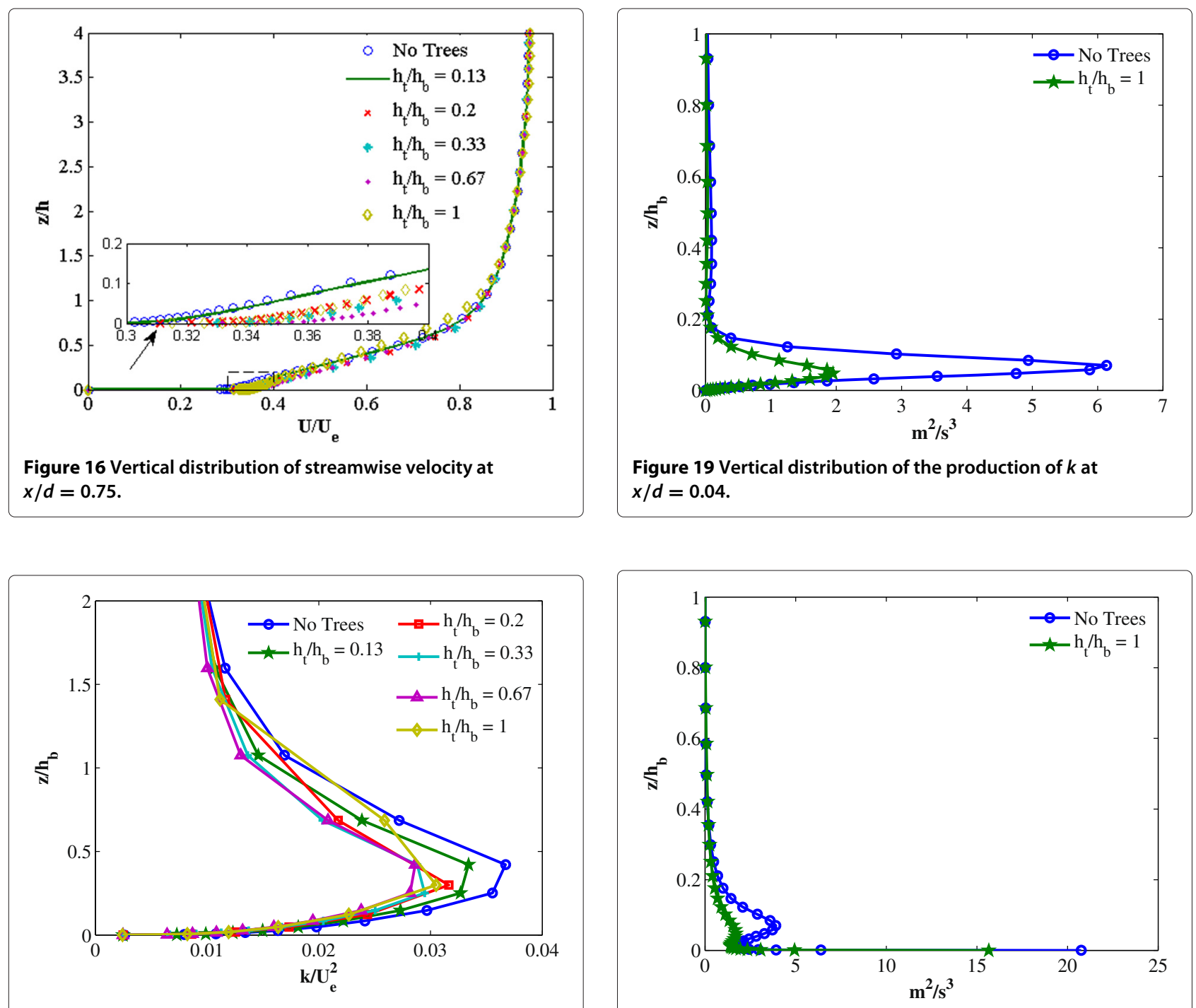

Figure 17 Vertical distribution of $k$ at $x / d=0.75$.

Figure 20 Vertical distribution of the dissipation at $x / d=0.04$.
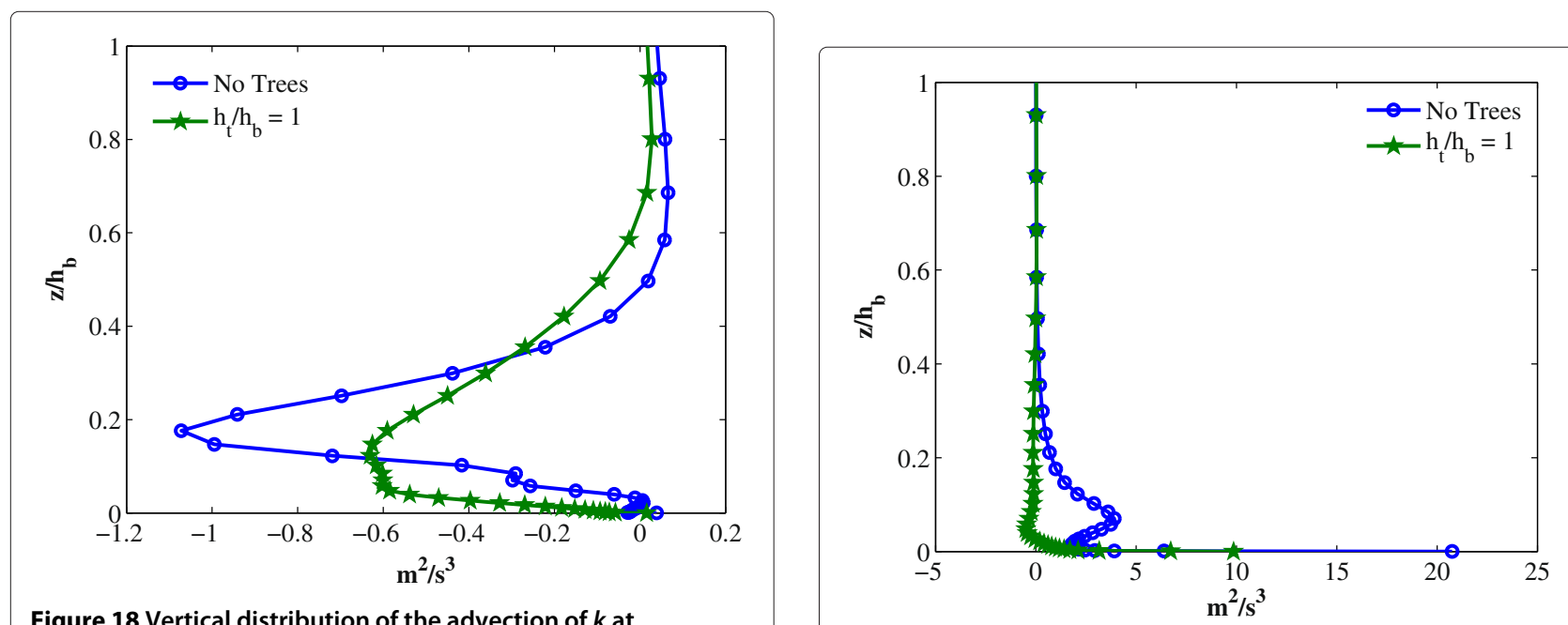

Figure 18 Vertical distribution of the advection of $k$ at $x / d=0.04$.

Figure 21 Vertical distribution of the diffusion of $k$ at $x / d=0.04$. 
The production term, $G_{K}$, in the $k-\epsilon$ turbulence model is given by

$$
\begin{aligned}
G_{K}= & v_{T}\left(2\left(\frac{\partial U}{\partial x}\right)^{2}+\left(\frac{\partial U}{\partial y}+\frac{\partial V}{\partial x}\right)^{2}+\left(\frac{\partial U}{\partial z}+\frac{\partial W}{\partial x}\right)^{2}\right. \\
& \left.+2\left(\frac{\partial V}{\partial y}\right)^{2}+\left(\frac{\partial V}{\partial z}+\frac{\partial W}{\partial y}\right)^{2}+2\left(\frac{\partial W}{\partial z}\right)^{2}\right)
\end{aligned}
$$

with the eddy viscosity $v_{T}=C_{\mu} k^{2} / \epsilon$.

Figures 18, 19, 20, and 21 display the individual terms of the $k$ budget. In terms of magnitude, the advection term is greater for the case without trees than the case with trees. This alone cannot fully justify the reduction of $k$ for the reason that follows in the next few sentences.

Without trees, there is increased advection and larger production of $k$ compared to the case with trees. Both results reflect the reduction in wind speed and its vertical gradient around $z / h_{b}=0.1$ that is shown in Figure 12 . The dissipation rate and diffusion of $k$ do not deviate as much between the two cases.

\section{Conclusions}

This study analyzed the effect on the wind field above the roof of a 15 - $\mathrm{m}$ high building $40 \times 50 \mathrm{~m}$ in plan of trees of varying height placed $40 \mathrm{~m}$ upwind of the building. The trees were varied in height from up to $15 \mathrm{~m}$. For comparison, the flow without trees was also calculated. Although the wind speed with trees does not exhibit a negative $\partial U / \partial z$, it does show a considerable difference when compared to the case without trees. The fact that even trees of height $2 \mathrm{~m}$ placed $40 \mathrm{~m}$ upwind of a $15-\mathrm{m}$ building can affect the flow above the roof suggests that they should be included when performing CFD simulations for buildings. The effect on wind speed was not monotonic with tree height as the greatest increase occurred for 12-m trees. The differences in wind speed, especially in Figure 12, and in the turbulent kinetic energy suggest that this generic geometry should be tested in a wind tunnel.

Generally, the trees decreased the turbulence over the roof which appears to be due to the reduction in production of turbulent energy as demonstrated by the energy balances in Figures 18, 19, 20 and 21.

\section{Competing interests}

The authors declare that they have no competing interests.

\section{Authors' contributions}

MAM formulated the tree model and performed all the computations. The test cases were developed by both authors. The paper was written jointly and both authors read and approved the final manuscript.

\section{Acknowledgments}

This paper reports on work sponsored by the Natural Science and Engineering Research Council and the ENMAX Corporation under the NSERC Industrial Research Chairs scheme.
Received: 18 June 2014 Accepted: 30 September 2014

Published online: 20 January 2015

\section{References}

Amorim, JH, Rodrigues, V, Tavares, R, Valente, J, Borrego, C (2013). CFD modelling of the aerodynamic effect of tree on urban air pollution dispersion. Science of the Total Environment, 461-462, 541-551.

Blocken, B, Janssen, W, van Hooff, T (2012). CFD simulation for pedestrian wind comfort and wind safety in urban areas: general decision framework and case study for the Eindhoven University campus. Environmental Modelling \& Software 30, 15-34.

Finnigan, J, \& Shaw, R (2008). Double-averaging methodology and its application to turbulent flow in and above vegetation canopies. Acta Geophysica, 56(3), 534-561.

Franke, J, Hirsch, C, Jensen, AG, Krüs, HW, Schatzmann, M, Westbury, PS, Miles, SD, Wisse, JA, Wright, NG (2004). Recommendations on the use of CFD in wind engineering, In COST Action C14, Impact of Wind and Storm on City Life Built Environment. Proceedings of the International Conference on Urban Wind Engineering and Building Aerodynamics, 5-7 May 2004, von Karman Institute, Sint-Genesius-Rode, Belgium, 14 (p. C1).

Hakimi, R, \& Lubitz, WD (2014). Wind environment at a roof-mounted wind turbine on a peaked roof building. International Journal of Sustainable Energy, doi:10.1080/14786451.2014.910516.

Hosoi, F, \& Omasa, K (2009). Estimating vertical leaf area density profile of tree canopies using three-dimensional portable LiDAR imaging, In Proceedings of the ISPRS workshop Laser-scanning, Paris, France. Available online at http://www.isprs.org/proceedings/XXXVIII/3-W8/papers/p55.pdf. Last accessed 1 December 2014, 9 (pp. 152-157).

Ishikawa, H, Amano, S, Yakushiji, K (2006). Flow around a living tree. JSME International Journal Series B 49(4), 1064-1069.

Jones, W, \& Launder, B (1972). The prediction of laminarization with a two-equation model of turbulence. International Journal of Heat and Mass Transfer 15(2), 301-314.

Kalmikov, A, Dupont, G, Dykes, K, Chan, C (2010). Wind power resource assessment in complex urban environments: MIT campus case-study using CFD Analysis, In AWEA 2010 WINDPOWER Conference. Dallas, USA; 2010 Available online at https://stuff.mit.edu/afs/athena/activity/w/wepa/ OldFiles/AWEA\%20Paper.pdf. Last accessed 1 December 2014.

Kolic, B (1978). Forest Ecoclimatology (in Serbian). UniversiScience of the, Belgrade, Yugoslavia.

Lalic, B, \& Mihailovic, DT (2004). An empirical relation describing leaf-area density inside the forest for environmental modeling. Journal of Applied Meteorology 43(4), 641-645.

Mohamed, M, \& Wood, D (2013). Vertical wind speed extrapolation using the $k-\varepsilon$ turbulence model. Wind Engineering 37(1), 13-36.

Raupach, M, \& Shaw, R (1982). Averaging procedures for flow within vegetation canopies. Boundary-Layer Meteorology 22(1), 79-90.

Tabrizi, AB, Whale, J, Lyons, T, Urmee, T (2014). Performance and safety of rooftop wind turbines: use of CFD to gain insight into inflow conditions. Renewable Energy 67, 242-251

Wilson, NR, \& Shaw, RH (1977). A higher order closure model for canopy flow. Journal of Applied Meteorology 16(11), 1197-1205. 